\title{
UMA HISTÓRIA DA BRITISH AND FOREIGN ANTI- SLAVERY SOCIETY: A INSTITUIÇÃO QUE INTERNACIONALIZOU O ANTIESCRAVISMO BRITÂNICO
}

Henrique Antonio Ré*

Universidade de São Paulo

São Paulo - São Paulo - Brasil

Resenha do livro: HEARTFIELD, James. The British and Foreign Anti-Slavery Society, 18381956. A history. Oxford: Oxford University Press, 2016. xii + 486p.

Em agosto de 1833, o Parlamento da Grã-Bretanha aprovou a lei que emancipou os escravos das colônias das Índias Ocidentais, do Canadá, da Colônia do Cabo e das Ilhas Maurício. (Essa lei não eliminou a escravidão do Império britânico, como alguns abolicionistas insistiram: ainda restavam os escravos das Índias Orientais, cujo número estimado superava todo o con-

\footnotetext{
* Pós-doutorando no Departamento de História, da Faculdade de Filosofia, Letras e Ciências Humanas da Universidade de São Paulo. E-mail: henrique.re@usp.br.
} 
junto de escravos das regiões do Novo Mundo). ${ }^{1}$ A lei de 1833 entrou em vigor a partir de $1^{\circ}$ de agosto de 1834; contudo, ela não tornou os ex-escravos imediatamente livres. Eles teriam que passar por um período de "aprendizado" para que se acostumassem à sua nova condição - na verdade, tratavase da regulamentação do trabalho forçado, com o objetivo de prolongá-lo por mais alguns anos. O "aprendizado" demonstrou ser um equívoco: ele desagradou aos abolicionistas, às autoridades coloniais, aos fazendeiros e, obviamente, aos aprendizes que, em muitos casos, viram sua situação piorar ainda mais. Diante da comoção pública e dos vários casos de abusos cometidos pelos fazendeiros e pelas autoridades coloniais, o Parlamento britânico resolveu reduzir os anos de prestação de serviço dos aprendizes. Em algumas ilhas, as próprias assembleias locais se encarregaram de acabar com o aprendizado antes mesmo da decisão do Parlamento britânico chegar às colônias. Assim, em $1^{\circ}$ de agosto de 1838, o sol se levantou sobre o Caribe trazendo uma liberdade um pouco mais pura para os negros britânicos, e todos os aprendizes foram considerados livres. ${ }^{2}$

Inegavelmente, a campanha antiescravista britânica, iniciada na década de 1780, alcançou um triunfo quase completo. Mas alguns grupos abolicionistas não ficaram satisfeitos com a indenização de vinte milhões de libras concedida pelo Estado britânico aos fazendeiros. Eles julgaram que a concessão da indenização somente seria legítima se a propriedade fosse legal, condição que não poderia ser aplicada à escravidão de seres humanos. Nas fileiras antiescravistas também havia indivíduos que não estavam contentes com a perspectiva de encerrar a campanha abolicionista. Eles desejavam levar a luta contra o tráfico e a escravidão para outras partes do mundo, numa cruzada mundial. Mas, nesse momento, as instituições antiescravistas britânicas existentes não estavam capacitadas para desempenhar esse novo papel.

A alternativa consistia, portanto, em criar uma nova entidade, que tivesse capilaridade por toda a Grã-Bretanha, mas que também contasse com auxílio e inserção internacional. Entretanto, em decorrência da existência de inúmeros grupos abolicionistas, cada um defendendo posições e métodos diferentes, mais uma vez o movimento antiescravista britânico se viu dividido quanto às medidas a serem adotadas e à forma de implantá-las.

\footnotetext{
TEMPERLEY, Howard. British antislavery, 1833-1870. Columbia: University of South Carolina Press, 1972, p. 94.

2 HUZZEY, Richard. Freedom burning. Anti-slavery and empire in Victorian Britain. Ithaca: Cornell University Press, 2012, p. 10-11.
} 
No final dos anos 1830, surgiram então duas entidades com pretensões de liderar a cruzada antiescravista mundial. Todavia, conforme um dos fundadores declarou, elas não eram rivais: como tinham focos diferentes, elas se complementavam. ${ }^{3}$

Thomas Fowell Buxton, um dos líderes abolicionistas mais reconhecidos e ativos naquele momento, vinha elaborando desde meados dos anos 1830 um projeto de colonização da África. A ideia consistia em estabelecer fazendas no continente africano para que servissem de modelo de desenvolvimento e desencorajassem os habitantes de participar do tráfico de escravos. Segundo Buxton, era necessário atuar para conter o tráfico de escravos, pois somente assim a escravidão poderia ser efetivamente eliminada. A instituição criada por Buxton, a Society for the Extinction of the Slave Trade and for the Civilization of Africa, organizou uma expedição ao rio Níger com o objetivo de implantar as fazendas, mas os integrantes da expedição foram assolados provavelmente pela malária, e o projeto de Buxton tornou-se uma tragédia. A Sociedade teve uma vida efêmera e foi dissolvida em 1843.

Outro grupo de abolicionistas, liderado por Joseph Sturge, um quacre de Birmingham, também vinha se organizando desde meados da década de 1830 para criar uma nova entidade, capaz de encabeçar a internacionalização do movimento abolicionista. Depois de várias reuniões no início do ano, surge em abril de 1839 a British and Foreign Anti-Slavery Society (BFASS), que existe até hoje ainda que com outro nome e, assim, é considerada a mais longeva instituição defensora dos direitos humanos.

Diferentemente da instituição de Buxton, a BFASS focou sua luta preferencialmente no combate à escravidão. Seus integrantes entendiam que, diante dos lucros do tráfico de escravos, de nada adiantaria combatê-lo diretamente, pois os traficantes sempre encontrariam uma forma de burlar qualquer tipo de bloqueio que lhes fosse imposto. Nessa perspectiva, combater a escravidão seria mais promissor, pois, uma vez eliminada a demanda, a oferta também seria extinta. Outra diferença da BFASS em relação a algumas sociedades abolicionistas anteriores era sua ênfase no imediatismo. Ela não via com bons olhos as medidas gradualistas para acabar com a escravidão e considerava que as vias institucionais eram os canais adequados para o avanço da causa antiescravista.

3 HUZZEY, Richard, op. cit., p. 67. 
Tal como a maioria das sociedades antiescravistas anteriores, a BFASS era comandada por quacres - o grupo religioso que seguramente esteve mais envolvido nas ações antiescravistas britânicas desde o final do século XVIII. Embora a BFASS fosse uma entidade de caráter civil, onde qualquer um poderia participar desde que contribuísse com uma pequena quantia, os quacres eram os principais responsáveis pela sua manutenção financeira, e, por isso, tinham o poder de definir sua orientação ideológica e suas diretrizes. Como os quacres eram defensores fervorosos do pacifismo, a BFASS jamais endossou qualquer atividade antiescravista que utilizasse as armas ou a força, nem apoiou qualquer proposta de intervenção antiescravista que pudesse gerar derramamento de sangue.

O livro de James Heartfield traça a história dessa instituição desde sua origem, em 1839, até sua última troca de nome em 1956. O recorte temporal da obra é bastante preciso. Por setenta anos, a BFASS atuou prioritariamente como uma entidade preocupada com o escravismo, mas tal preocupação foi assumindo outros contornos a partir do final do século XIX, especialmente em decorrência da colonização da África pelas potências europeias. Em 1909, a BFASS se fundiu com a Aborigines' Protection Society e transformou-se em Anti-Slavery and Aborigines' Protection Society. Depois das duas guerras mundiais, ainda que a questão escravista fosse um assunto de extrema relevância, o início da luta contra o colonialismo na África e as discussões acerca da igualdade de direitos entre negros e brancos levaram a Sociedade a procurar "seus apoiadores para uma possível troca de nome, 'que express[ass]e mais corretamente a extensão de suas atividades'" (p. 421). Em 1956, ela assumiu sua designação atual: Anti-Slavery Society for the Protection of Human Rights. No início do século XX, ela já havia atuado em várias ocasiões na Liga das Nações; depois da criação da ONU, a Sociedade continuou atuando como uma espécie de órgão consultivo.

Embora outros trabalhos já tivessem tratado da história da BFASS, nenhum o fez com tamanha abrangência. Em geral, as obras anteriores eram compilações de seus "feitos" (por vezes, uma espécie de prestação de contas organizada pela própria entidade), ou obras historiográficas que abordavam a participação da BFASS no movimento antiescravista britânico ou em contextos específicos. ${ }^{4}$ Enfim, é a primeira vez que surge uma obra exclusiva-

\footnotetext{
${ }^{4}$ Ver, por exemplo, A chronological summary of the work of the British $\&$ Foreign Anti-Slavery Society during the nineteenth century (1839-1900). Londres: Offices of the Society, 1901; HARRIS, John. A century of emancipation. Londres: Kennikat Press, 1971. Harris foi secretário da
} 
mente voltada para a história dessa instituição e abrangendo todo o período no qual ela se dedicou prioritariamente à causa do antiescravismo.

Obviamente, como o próprio subtítulo do livro esclarece, trata-se de "uma história" dentre as inúmeras possíveis, especialmente quando se leva em consideração que o recorte temporal abarca um período de aproximadamente cento e vinte anos, no qual a instituição se envolveu em diversos assuntos em várias regiões do mundo, e respondeu de formas variadas aos desafios que se apresentavam.

Heartfield adotou uma forma expositiva que privilegia os temas principais nos quais a BFASS esteve envolvida, trabalhando-os separadamente em cada um dos capítulos. A narrativa segue uma sequência em que, na primeira parte do livro, são abordados os temas referentes à escravidão nas Américas; na segunda, a escravidão na África; e, na terceira, o trabalho contratado nas colônias das Índias Ocidentais e da África, e o posicionamento da Sociedade no período entre-guerras. Ao mesmo tempo em que essa estratégia expositiva permitiu maior leveza no tratamento dos assuntos, também dificultou o aprofundamento em alguns deles, como foi o caso do envolvimento da BFASS na escravidão cubana e brasileira ou na diplomacia britânica que atuou contra o tráfico de escravos. Tornou-se praticamente impossível abordar de maneira mais circunstanciada a forma como a Sociedade lidou com essas situações no decorrer das décadas em que esteve envolvida nestes casos.

Outro mérito do livro foi acompanhar a transformação da atuação da BFASS, que atendia às mudanças que ocorriam nas formas de trabalho - da escravidão nas Américas e na África para o trabalho contratado dos chineses e indianos nas Américas, na África, na Ásia e na Oceania, em áreas não necessariamente sob domínio britânico. A Sociedade combatia a utilização dessa forma de trabalho, mas apresentava como um dos motivos para recusá-lo a imoralidade dos trabalhadores: em muitos casos, alegava a BFASS, tratava-se de prostitutas, homossexuais e viciados de péssimo caráter (p. 341-2).

Contudo, a linha mestra que organiza toda a narrativa, ainda que em vários momentos não esteja claramente exposta, é uma sugerida interação entre a BFASS e o governo britânico. O autor evidencia essa perspectiva já a partir da primeira página da obra: “(...) a Sociedade ajudou a estabelecer os fundamentos de uma sociedade civil esclarecida; mas ao mesmo tempo

Anti-Slavery and Aborigines' Protection Society a partir de 1910; a primeira edição de seu livro ocorreu em 1933; TEMPERLEY, Howard, op. cit.; HUZZEY, Richard, op. cit. 
esteve intimamente ligada ao Estado, baseou-se em relatórios oficiais, elaborou propostas de diretrizes e até engendrou a criação de um departamento antiescravista paralelo dentro do governo". A atuação da BFASS também teria transformado concomitantemente o antiescravismo num mecanismo de projeção governamental britânica (p. 1).

Essa tensão perpassa toda a obra, e o autor teve méritos em demonstrar como a BFASS, ao apoiar a diplomacia contra o tráfico de escravos, ajudou indiretamente a estabelecer uma espécie de tutoria sobre os países que participavam dos tratados ou acordos bilaterais com a Grã-Bretanha para acabar com esse comércio e, consequentemente, difundir mais amplamente os interesses britânicos. Da mesma forma, a retórica antiescravista tornou-se um ingrediente do pacote ideológico que justificou a subjugação dos povos coloniais africanos a partir da década de 1870: paradoxalmente, a retórica abolicionista já continha as sementes do império (p. 75 e 229).

É certo que a BFASS se esforçou para impor certa diretriz abolicionista à política internacional britânica, mas é difícil conceber que ela dispunha de força suficiente para fazê-lo. Em 1841, sua pressão sobre o governo para que ministros, cônsules e agentes no exterior não negociassem escravos foi bem sucedida. Palmerston, então ministro do Foreign Office, enviou uma circular a todas as representações britânicas no exterior para que adotassem essa resolução, que havia sido elaborada pelo primeiro Congresso Antiescravista Mundial, organizado pela BFASS, em Londres, em meados de $1840 .^{5}$ Não é difícil perceber, entretanto, que tal medida tinha pouca capacidade de influenciar os destinos da escravidão nos países escravistas. Tratava-se mais de uma questão de moralidade.

Portanto, o autor parece exagerar um pouco a interação entre a BFASS e o governo britânico. Se a Sociedade utilizava os relatórios consulares para elaborar seus estudos e matérias sobre o tráfico e a escravidão, ela também obtinha dados de outras fontes; por exemplo, de seus correspondentes no exterior, ou do caso extremo em que enviou uma missão secreta ao Brasil para coletar informações sobre a situação do tráfico e da escravidão. ${ }^{6}$ A utilização dos relatórios consulares não era exclusividade da BFASS, pois eles

\footnotetext{
5 Ver, por exemplo, as correspondências de Palmerston aos representantes consulares britânicos no Brasil em FO 84/326, National Archives, Londres.

6 Sobre a missão enviada ao Brasil, ver RÉ, Henrique Antonio. "Missão nos Brasis": a BFASS e a organização de uma missão abolicionista secreta ao Brasil no início da década de 1840. Revista de História, n. 174, São Paulo, jan.-jun. 2016, p. 69-100.
} 
eram ansiosamente lidos em Madri, Havana e Rio de Janeiro, e o governo brasileiro chegou a utilizá-los como dados oficiais. ${ }^{7}$

Ainda que a BFASS também tivesse acesso às autoridades governamentais e tentasse influenciar politicamente as diretrizes antiescravistas do Estado britânico, isso em geral ocorria por meio de lobby parlamentar. A Sociedade procurava os parlamentares simpáticos à causa e os orientava sobre a maneira de proceder, de acordo com aquilo que julgava mais adequado para determinada questão. Nesses casos, provavelmente, o máximo que ela conseguiu foi a adesão de um ou outro parlamentar mais recalcitrante ou a flexibilização de algumas posturas mais conservadoras. Em muitas ocasiões, a BFASS viu seu pleito ser vencido nos gabinetes ou nas votações, como ocorreu, por exemplo, na anexação do Texas, no Tratado Webster-Ashburton, na questão da equalização dos impostos do açúcar e na repressão ao tráfico brasileiro no início da década de 1850. Como um historiador salientou, os abolicionistas muitas vezes tentaram confrontar a exploração escravista em qualquer país a partir de táticas de natureza moral, religiosa e pacífica, mas isso proporcionava uma base relativamente pequena para interferir nas diretrizes do Estado britânico. Além disso, desde a fundação da BFASS, alguns de seus principais membros ganharam a reputação de idealistas irresponsáveis. ${ }^{8}$

Seguramente, a difusão dos interesses comerciais, diplomáticos e políticos da Grã-Bretanha foi beneficiada pela retórica antiescravista tanto na metrópole quanto no exterior, dentro ou fora do Império britânico. Entretanto, são muito bem conhecidas pela historiografia as divergências entre o Comitê da BFASS e as autoridades políticas e militares britânicas. Em várias ocasiões, as decisões da Sociedade desagradaram os estadistas britânicos e, principalmente, os comandantes militares responsáveis pelo esquadrão naval estacionado na costa africana e americana. ${ }^{9}$ Portanto, supor uma interação entre a BFASS e o Estado britânico, como se a entidade antiescravista

7 ELTIS, David. Economic growth and the end of the transatlantic slave trade. Nova York: Oxford University Press, 1987, p. 112.

${ }^{8}$ HUZZEY, Richard, op. cit., p. 67-8; TURLEY, David. Anti-slavery activists and officials: "influence", lobbying and the slave trade, 1807-1850. In: HAMILTON, Keith $\mathcal{E}$ SALMON, Patrick. Slavery, diplomacy and empire. Britain and the suppression of the slave trade, 1807-1975. Londres: Sussex Academic Press, 2013, p. 88-90.

9 Ver, por exemplo, o episódio em que Charles Fitzgerald, um tenente da Marinha Real, foi proibido por Sturge de se pronunciar no Congresso Antiescravista Mundial de 1840, pois ele se opunha ao "princípio pacífico" do referido congresso. HUZZEY, Richard, op. cit., p. 14. 
estivesse "intimamente ligada ao Estado", é um ponto de vista que talvez precise ser relativizado.

Outro ponto que merece ser mencionado na obra de Heartfield - mais pela ausência do que pela presença - é a participação dos negros no próprio processo de emancipação ou, para usar um termo horrível, mas bastante utilizado hoje em dia, a "agência escrava". É o próprio autor que afirma:

A escravidão é um ato belicoso e a mão-de-obra forçada estava sempre disposta a resistir e, muitas vezes, a se revoltar. As revoltas de escravos eram dispendiosas em termos de tropas e gastos militares e onerosas em matéria de prestígio para os governos europeus. Tão importante quanto o movimento de emancipação na Inglaterra era a recusa constante dos próprios escravos de não se deixar escravizar (p. 17).

Embora o capítulo 1 apresente um item chamado "Revoltas escravas", em que é mencionado o protagonismo dos escravos no processo de abolição de alguns países, infelizmente, o autor não dedicou outros momentos para compreender por que a BFASS sempre declinou de qualquer participação direta dos ex-escravos na luta contra a escravidão nas colônias ou em outros países.

É certo que Joseph Sturge, o fundador da BFASS, e outros abolicionistas se dedicaram pessoalmente a empreendimentos nas colônias para a educação dos ex-escravos e para o estabelecimento de pequenas propriedades, mas não há registros de que a BFASS tenha aceitado ou incentivado a participação dos escravos e ex-escravos na luta abolicionista nas colônias britânicas. Essa recusa, provavelmente, não decorria exclusivamente de seu pacifismo, mas da maneira como entendia que a emancipação devia ser conduzida: sempre de forma ordeira, preservando o status quo e pela via legislativa. Qualquer ato que pudesse vir a prejudicar a produção e a economia ou que se desviasse dos padrões sociais britânicos deveria ser desprezado. Uma vez que o autor se preocupou em mencionar o tema da revolta escrava, ele poderia ter investigado um pouco mais a relação da BFASS com o protagonismo negro.

\section{A BFASS e o Brasil}

Embora seja correto afirmar que a abolição brasileira "nunca foi a principal prioridade da Sociedade" (p. 189), desde a sua fundação, a BFASS expressou preocupação com o tráfico e a escravidão brasileira, tanto que em seu Estatuto o nome do Brasil aparece ao lado dos Estados Unidos, do Texas e 
de Cuba como os locais para onde a Sociedade deveria dirigir seus esforços. ${ }^{10}$ Mas a preocupação da BFASS com o Brasil não esteve apenas formulada em seu Estatuto. Desde o início da década de 1840 até a abolição da escravidão brasileira, em 1888, a Sociedade realizou esforços para combater o escravismo no Brasil. A historiografia já documentou a relação entre Joaquim Nabuco e a BFASS na década de 1880; também já é conhecida a missão organizada secretamente pela BFASS no início da década de 1840 para investigar as condições da escravidão no país; do mesmo modo, são conhecidas as petições que a BFASS e outras sociedades antiescravistas auxiliares da Grã-Bretanha (ligadas à BFASS) enviaram ao imperador e às autoridades governamentais brasileiras, pressionando primeiramente pelo fim do tráfico e depois pelo término da escravidão. ${ }^{11}$

Infelizmente, nesse ponto, o livro de Heartfield é bastante sucinto e apresenta alguns equívocos. Todo o envolvimento da BFASS com Brasil e Cuba é abordado num único capítulo de pouco mais de vinte páginas. Tratando especificamente do caso brasileiro, pode-se afirmar que Heartfield se limitou a comentar alguns aspectos do Bill Aberdeen, do envolvimento do capital britânico em atividades escravistas brasileiras e de algumas petições contra a escravidão enviadas ao Brasil.

Além dos erros na grafia de alguns nomes, Heartfield se equivoca quando diz que "o líder da Sociedade para a Abolição do Tráfico de Escravos na década de 1870 era Joaquim Nabuco" (p. 194). Além dessa Sociedade nunca ter existido no Brasil, Joaquim Nabuco, no início da década de 1870, estava concluindo seu curso de Direito no Recife e logo depois viajaria para a Europa, onde passaria anos em estado de "lazaronismo intelectual", como ele próprio reconheceu. ${ }^{12}$ Logo depois, graças aos contatos paternos, assumiria cargos diplomáticos nos Estados Unidos e na Inglaterra. Somente após a morte do pai e de sua eleição para a Câmara dos Deputados, em 1878, Nabuco se manifestaria no ano seguinte publicamente contra a escravidão.

Outro sério equívoco da obra de Heartfield foi afirmar que "a Lei 3.353, de 13 de maio de 1888, foi proclamada em nome do Príncipe Imperial Re-

\footnotetext{
${ }^{10}$ British and Foreign Anti-Slavery Society for the abolition of slavery and slave-trade throughout the world. Address. Londres: Johnston and Barrett, s.d. [1839?], p. 2.

${ }^{11}$ BETHELL, Leslie $\mathcal{E}$ CARVALHO, José Murilo de (org.). Joaquim Nabuco e os abolicionistas britânicos. Correspondência, 1880-1905. Rio de Janeiro: Topbooks, 2008; ROCHA, Antonio Penalves. Abolicionistas brasileiros e ingleses. A coligação entre Joaquim Nabuco e a British and Foreign Anti-Slavery Society (1880-1902). São Paulo: Editora da Unesp, 2009.

${ }^{12}$ NABUCO, Joaquim. Minha formação. Brasília: Editora Universidade de Brasília, 1963, p. 173.
} 
gente, Rodrigo Augusta [sic] da Silva" (p. 195). O autor estava se referindo ao senador Rodrigo Silva, que na época ocupava ao mesmo tempo os ministérios da Agricultura, Comércio e Obras Públicas e dos Negócios Estrangeiros, e foi o autor do projeto da referida lei.

São nos equívocos sobre o Brasil, provavelmente, que se manifesta mais claramente uma das deficiências dessa obra. Heartfield realizou uma ampla pesquisa sobre a BFASS, que abarcou quase cento e vinte anos de atuação de uma instituição que possuía capilaridade em várias regiões do mundo. Esse é um mérito que deve ser reconhecido. Porém, talvez devido às dificuldades de lidar com outras línguas, o autor se limitou somente à historiografia de origem anglo-saxã. E, no caso das fontes provenientes da BFASS, ele se limitou basicamente ao material impresso, em especial o Anti-Slavery Reporter, que era o periódico da Sociedade, e os Annual Reports. Heartfield não utilizou nenhuma vez sequer a correspondência trocada entre os membros do Comitê da BFASS e os correspondentes no exterior, tombada pela Rhodes House Library de Oxford, que guarda precioso material que não pôde ser publicado na época.

A análise dessa correspondência talvez permitisse que o autor percebesse a ambivalência do posicionamento da BFASS. ${ }^{13}$ A Sociedade desejava a extinção da escravidão por meio de métodos pacíficos, legais e economicamente viáveis, sempre de acordo com as concepções britânicas de liberdade e da organização liberal da economia. Entretanto, a BFASS tinha dificuldades para perceber ou aceitar que esses padrões sociais e econômicos dificilmente poderiam ser implantados sem ferir muitas crenças liberais. Em outras palavras, a BFASS não conseguia explicar como o fim da escravidão nas Índias Ocidentais levou ao colapso da produção açucareira, nem como a aplicação das diretrizes do livre-comércio ao tráfico de escravos geraria um salto grandioso desse comércio ou como o livre-comércio do açúcar favorecia a escravidão em Cuba e no Brasil.

\section{Referências bibliográficas}

A chronological summary of the work of the British $\mathcal{E}$ Foreign Anti-Slavery Society during the nineteenth century (1839-1900). Londres: Offices of the Society, 1901.

BETHELL, Leslie $\mathcal{E}$ CARVALHO, José Murilo de (org.). Joaquim Nabuco e os abolicionistas britânicos. Correspondência, 1880-1905. Rio de Janeiro: Topbooks, 2008.

\footnotetext{
${ }^{13}$ Sobre a questão da ambivalência do posicionamento dos abolicionistas, ver ELTIS, David, op. cit., especialmente o capítulo 7.
} 
British and Foreign Anti-Slavery Society for the abolition of slavery and slave-trade throughout the world. Address. Londres: Johnston and Barrett, s.d. [1839?].

ELTIS, David. Economic growth and the end of the transatlantic slave trade. Nova York: Oxford University Press, 1987.

Foreign Office, Série 84, National Archives, Londres.

HARRIS, John. A century of emancipation. Londres: Kennikat Press, 1971.

HUZZEY, Richard. Freedom burning. Anti-slavery and empire in Victorian Britain. Ithaca: Cornell University Press, 2012.

NABUCO, Joaquim. Minha formação. Brasília: Editora Universidade de Brasília, 1963.

RÉ, Henrique Antonio. "Missão nos Brasis": a BFASS e a organização de uma missão abolicionista secreta ao Brasil no início da década de 1840. Revista de História, n. 174, São Paulo, jan.-jun. 2016, p. 69-100.

ROCHA, Antonio Penalves. Abolicionistas brasileiros e ingleses. A coligação entre Joaquim Nabuco e a British and Foreign Anti-Slavery Society (1880-1902). São Paulo: Editora da Unesp, 2009.

TEMPERLEY, Howard. British antislavery, 1833-1870. Columbia: University of South Carolina Press, 1972.

TURLEY, David. Anti-Slavery activists and officials: "influence", lobbying and the slave trade, 1807-1850. In: HAMILTON, Keith \& SALMON, Patrick. Slavery, diplomacy and empire. Britain and the suppression of the slave trade, 1807-1975. Londres: Sussex Academic Press, 2013.

Recebido: 03/05/2017 - Aprovado: 08/06/2017 